\title{
Desenvolvimento e caracterização físico-química, microbiológica e sensorial de bebida láctea fermentada elaborada com diferentes estabilizantes/espessantes
}

\section{Development and physical-chemical, microbiological and sensory characterization of fermented dairy beverage prepared with different stabilizers/thickener}

\author{
Alexsandra Valéria Sousa Costa ${ }^{1 *}$; Edmar Soares Nicolau ${ }^{2}$; \\ Maria Célia Lopes Torres ${ }^{3}$; Patrícia Rodrigues Fernandes ${ }^{4}$; \\ Sarah Inês Rodrigues Rosa ${ }^{5}$; Rakel Cândido Nascimento ${ }^{5}$
}

\section{Resumo}

\begin{abstract}
Este trabalho foi realizado com o objetivo de avaliar as características físico-químicas, sensoriais e a qualidade microbiológica de bebidas lácteas fermentadas elaboradas com $10 \%$ de sacarose, $50 \%$ de leite e $50 \%$ de soro de queijo e adicionadas de cinco diferentes estabilizantes/espessantes em duas concentrações $(0,50 \%$ e $1,00 \%$ em relação à formulação final), propondo uma formulação com boa aceitação. Foram desenvolvidos dez tratamentos: PCPS $1,00 \%=$ proteína $(0,50 \%)$ e concentrado proteico de soro $(0,50 \%)$; GP $1,00 \%=$ gelatina em pó $(1,00 \%)$; GG $1,00 \%=$ goma guar $(1,00 \%)$; AM $1,00 \%=$ amido de milho $(1,00 \%)$; GGCMC $1,00 \%=$ goma guar $(0,50 \%)$ e carboximetilcelulose $(0,50 \%)$; PCPS $0,50 \%=$ proteína $(0,25 \%)$ e concentrado proteico de soro $(0,25 \%)$; GP $0,50 \%=$ gelatina em pó $(0,50 \%)$; GG $0,50 \%=$ goma guar $(0,50 \%)$; AM $0,50 \%=$ amido de milho $(0,50 \%)$; GGCMC $0,50 \%=$ goma guar $(0,25 \%)$ e carboximetilcelulose $(0,25 \%)$. As bebidas lácteas fermentadas foram avaliadas quanto ao $\mathrm{pH}$, acidez em ácido lático, umidade, cinzas, lipídios, proteína, viscosidade, sinérese, aceitação sensorial (escala hedônica de nove pontos) e contagem de coliformes a $35^{\circ} \mathrm{C}$ e $45^{\circ} \mathrm{C}$. Os resultados obtidos, submetidos a ANOVA e teste de médias (nível de significância a 5\%), revelaram que os tipos e as porcentagens dos estabilizantes/espessantes influenciaram principalmente os valores de sinérese, viscosidade e aceitação das amostras. Dos tratamentos estudados aqueles contendo proteína e concentrado proteico de soro $(1,00 \%)$, goma guar $(1,00 \%)$ e gelatina $(0,50 \%)$ apresentaram viscosidade/consistência similiar/compatível com iogurte e bebidas lácteas fermentadas comerciais e não apresentaram sinérese, após processamento. Sob o ponto de vista microbiológico, todas as amostras estavam aptas para serem consumidas, segundo a legislação vigente. $\mathrm{O}$ tratamento com $0,50 \%$ de gelatina destacou-se pelos melhores resultados de aceitação para a aparência, aroma, cor e textura.
\end{abstract}

Palavras-chave: Hidrocolóides, leite, retenção, soro lácteo, viscosidade

\footnotetext{
${ }^{1}$ MSc. em Ciência e Tecnologia de Alimentos, Doutoranda em Ciência Animal, Universidade Federal de Goiás, Escola de Veterinária e Zootecnia, UFG, Goiânia, GO. E-mail: alexsandratecla@yahoo.com.br

${ }^{2}$ Prof. Dr. em Engenharia de Alimentos, UFG, Goiânia, GO. E-mail: rena@cpa.vet.ufg.br

${ }^{3}$ Profa'. Dr ${ }^{\mathrm{a}}$. em Ciência e Tecnologia de Alimentos, Goiânia, GO. E-mail: celialopes.ufg@gmail.com

${ }^{4}$ Engenheira de Alimentos, UFG, Centro de Pesquisa em Alimentos, Goiânia, GO. E-mail: patricia_engalimentos@hotmail.com

${ }^{5}$ Veterinárias, UFG, Goiânia, GO. E-mail: sarahines.vet@gmail.com; rakelcandidovet@hotmail.com

* Autor para correspondência
} 


\begin{abstract}
This study was conducted to evaluate the physical-chemical, sensory and microbiological characteristics of fermented dairy beverages prepared with $10 \%$ sucrose, $50 \%$ milk and $50 \%$ whey and added five different stabilizers/thickeners in two concentrations $(0,50 \%$ and $1,00 \%$ in relation to the final formulation). Ten treatments have been developed: PCPS $1,00 \%=$ protein $(0,50 \%)$ and whey protein concentrate $(0,50 \%)$; GP $1,00 \%=$ powdered gelatin $(1,00 \%)$; GG $1,00 \%=$ guar gum $(1,00 \%)$; AM $1.00 \%=$ corn starch $(1,00 \%)$; GGCMC $1,00 \%=$ guar gum $(0,50 \%)$ and carboxymethylcellulose $(0,50 \%)$; PCPS $0,50 \%=$ protein $(0,25 \%)$ and whey protein concentrate $(0,25 \%)$; GP $0.50 \%=$ powdered gelatin $(0,50 \%)$; GG $0.50 \%=$ guar $(0,50 \%)$; AM $0,50 \%=$ corn starch $(0,50 \%)$; GGCMC $0,50 \%=$ guar gum $(0,25 \%)$ and carboxymethylcellulose $(0,25 \%)$. The fermented dairy beverages were evaluated for $\mathrm{pH}$, acidity in lactic acid, moisture, ash, fat, protein, viscosity, syneresis, sensory acceptance (in a nine-point hedonic scale) and count of coliforms at $35^{\circ} \mathrm{C}$ and $45^{\circ} \mathrm{C}$. The results were submitted to ANOVA and mean test with significance level of 5\%. It was observed that the types and percentages of stabilizers/thickeners mainly influenced the values of syneresis, viscosity and acceptance of samples. Those of the treatments containing protein and whey protein concentrate $(1,00 \%)$, guar gum $(1,00 \%)$ and gelatin $(0,50 \%)$ showed viscosity/consistency similiar/compatible with yogurt and commercial fermented dairy beverages and showed no syneresis, after processing. All formulations were safe to be consumed considering the microbiological results and according to the legislation. The treatment with $0,50 \%$ gelatin stood out for the best acceptance for appearance, aroma, color and texture.
\end{abstract}

Key words: Hydrocolloids, milk, retention, whey, viscosity

\section{Introdução}

As mudanças no comércio de gêneros alimentícios e a crescente exigência do consumidor por alimentos que apresentem, além da alta qualidade sensorial e nutricional, benefícios associados à saúde, aumentam a demanda de novos produtos que possam atender a estas exigências do mercado (BASTIANI, 2009). Entre os atributos dos alimentos que têm preocupado os consumidores, destacam-se o teor e o tipo de gordura. O consumo de alimentos com baixo teor de gordura reduz o risco de vários tipos de doenças, tais como a obesidade, a hipertensão, a apoplexia cerebral e doenças cardíacas coronárias (SANDOVAL-CASTILLA et al., 2004; YOO et al., 2007).

$\mathrm{Na}$ indústria de alimentos, a formulação de alimentos sem a adição de gorduras constitui um grande desafio, pois a gordura apresenta várias propriedades que afetam textura, aparência, sabor e aroma (GONZÁLEZ-TOMÁSA et al., 2008). Assim, diversos produtos têm sido avaliados como substitutos da gordura nas formulações. Entre eles, o soro de queijo, um subproduto da indústria de laticínios, tem despertado o interesse de vários pesquisadores em todo o mundo pela sua potencialidade nutricional, funcional $\mathrm{e}$ econômica. $\mathrm{Na}$ forma de concentrado proteico vem sendo aplicado pela indústria de alimentos em produtos dietéticos, modificando as propriedades de textura (ANTUNES; CAZETTO; BOLINI, 2004) e melhorando as propriedades nutricionais e funcionais, principalmente, pelo teor de aminoácidos sulfurados presentes (SINHÁ et al., 2007; SMITHERS, 2008).

O soro de queijo é um líquido opaco, amareloesverdeado e que contém aproximadamente 55\% dos sólidos existentes no leite integral original, representando em torno de 80 a $90 \%$ do volume de leite utilizado na fabricação de queijo. Possui uma Demanda Bioquímica de Oxigênio (DBO) entre 30.000 e $60.000 \mathrm{mg}$ de $\mathrm{O}_{2} \mathrm{~L}^{-1}$ e, em média, cada tonelada de soro não tratado despejado por dia equivale à poluição diária de cerca de 470 pessoas (ANDRADE; MARTINS, 2002). É um resíduo de alto valor biológico e baixo valor comercial, que causa um grande impacto ambiental quando descartado sem o devido tratamento. Dessa forma, o reaproveitamento do soro líquido, além de 
contribuir para a melhoria do meio ambiente, pode proporcionar ganhos às indústrias (MATOS, 2009).

A utilização de soro de queijo, na forma de concentrado proteico, na elaboração de bebidas lácteas constitui um modo racional de aproveitamento desse produto secundário que, além das características nutricionais, é capaz de conferir propriedades tecnológicas desejáveis e adequadas em aplicações específicas (BASTIANI, 2009). A combinação de um alimento suplementado com proteínas e fermentado por microrganismos probióticos pode gerar um produto com propriedades tecnológicas e funcionais que atendam demandas por produtos saudáveis (SILVA; ABREU; ASSUMPÇÃO, 2012).

Estudos mostram que o soro de queijo, na forma de concentrado proteico, apresenta capacidade emulsificante, geleificante e de retenção de água, adequada viscosidade e adesividade, retêm e incorporam gordura, facilitam o batimento, a formação de espuma e aeração, realçam a cor, o sabor e a textura (REGESTER et al., 1996; SODINI; MONTELLA; TONG, 2005). A incorporação de biopolímeros, especialmente proteínas e hidrocolóides, representa uma das estratégias mais comuns utilizados para estabilizar emulsões alimentares (MCCLEMENTS, 2007; DICKINSON, 2009). Alguns dos ingredientes que acrescidos ao leite aumentam a firmeza do iogurte são: o leite em pó integral ou desnatado, soro ou concentrado proteico do soro de queijo, caseinato, amido modificado, pectina, gelatina e gomas (DANNENBERG; KESSLER, 1988).

As proteínas do soro apresentam uma grande variedade de utilizações em alimentos, devido às suas propriedades de solubilidade, de viscosidade, de retenção de água, de gelificação e de emulsificação (HUFFMAN, 1996). Os hidrocolóides têm sido amplamente utilizados na estabilização estrutural de produtos lácteos fermentados (KOKSOY; KILIC, 2004), geralmente atuam através do aumento da viscosidade ou formando uma rede de gel dentro da fase de dispersão; atrasando assim os processos de instabilidade e agem como uma estruturação, espessamento e agente estabilizante no meio aquoso (MCCLEMENTS, 2007; DICKINSON, 2009). O amido, um dos agentes espessantes mais amplamente utilizados na indústria, pode melhorar as características de determinados alimentos em relação a sinérese e a consistência (MALI et al., 2003). A carboximetilcelulose (CMC) está sendo utilizada como uma alternativa ao amido nos produtos alimentares devido às suas vantagens tecnológicas e nutricionais (BAYARRI; CHULIÁ; COSTELL, 2010).

As gomas e a gelatina são utilizadas como espessantes/estabilizantes em iogurtes convencionais, conferindo-lhes aumento na consistência e redução da sinérese (MANZANO et al., 2008). A ação das gomas inclui basicamente a retenção de água e o aumento da viscosidade. A goma guar produz soluções viscosas e é usada em aplicações, nas quais é necessário espessamento, estabilização, controle reológico e de viscosidade, suspensão e formação de corpo, modificação de textura e consistência e retenção de água. Em produtos de laticínios, fornece textura macia e reduz a sinérese (DZIEZAK,1991; SANDERSON, 1996). A gelatina é outro estabilizante normalmente utilizado em produtos lácteos fermentados, que deve a sua importância a característica reológica original em propiciar a textura de "derreter na boca" típica de um gel de gelatina (MARCOTTE, HOSHAHITI, RAMASWAMY, 2001), também é utilizada para aumentar a viscosidade, firmeza e evitar a separação do soro em iogurte (KEOGH; O'KENNEDY, 1998; FISZMAN; LLUC SALVADOR, 1999).

Bebidas à base de soro de queijo permitem o retorno desse composto à alimentação (CRUZ et al., 2008), sendo indicada sua adição nos produtos lácteos pela capacidade de formação de gel, aumento da viscosidade, poder emulsificante e capacidade de retenção de água, conferindo benefícios estruturais e nutricionais ao produto final (BELLARDE, 2006). 
Assim, este trabalho foi realizado com o objetivo de avaliar as características físicoquímicas, sensoriais e a qualidade microbiológica de bebidas lácteas fermentadas elaboradas com $50 \%$ de leite e $50 \%$ de soro de queijo e adicionadas de cinco diferentes estabilizantes/espessantes em duas concentrações, propondo um produto com características adequadas e boa aceitação sensorial.

\section{Material e Métodos}

\section{Matéria-prima}

Os estabilizantes/espessantes, o açúcar e o leite pasteurizado padronizado com teor de gordura em $3 \%$ (informações na embalagem) foram adquiridos do mercado varejista do município de Goiânia, GO. O soro de queijo minas frescal foi obtido conforme procedimento descrito por Alves (2010), Hofmeister et al. (2005) e Martins et al. (2012), com algumas modificações (Figura 1).

Figura 1. Fluxograma de obtenção do soro de queijo tipo minas frescal.

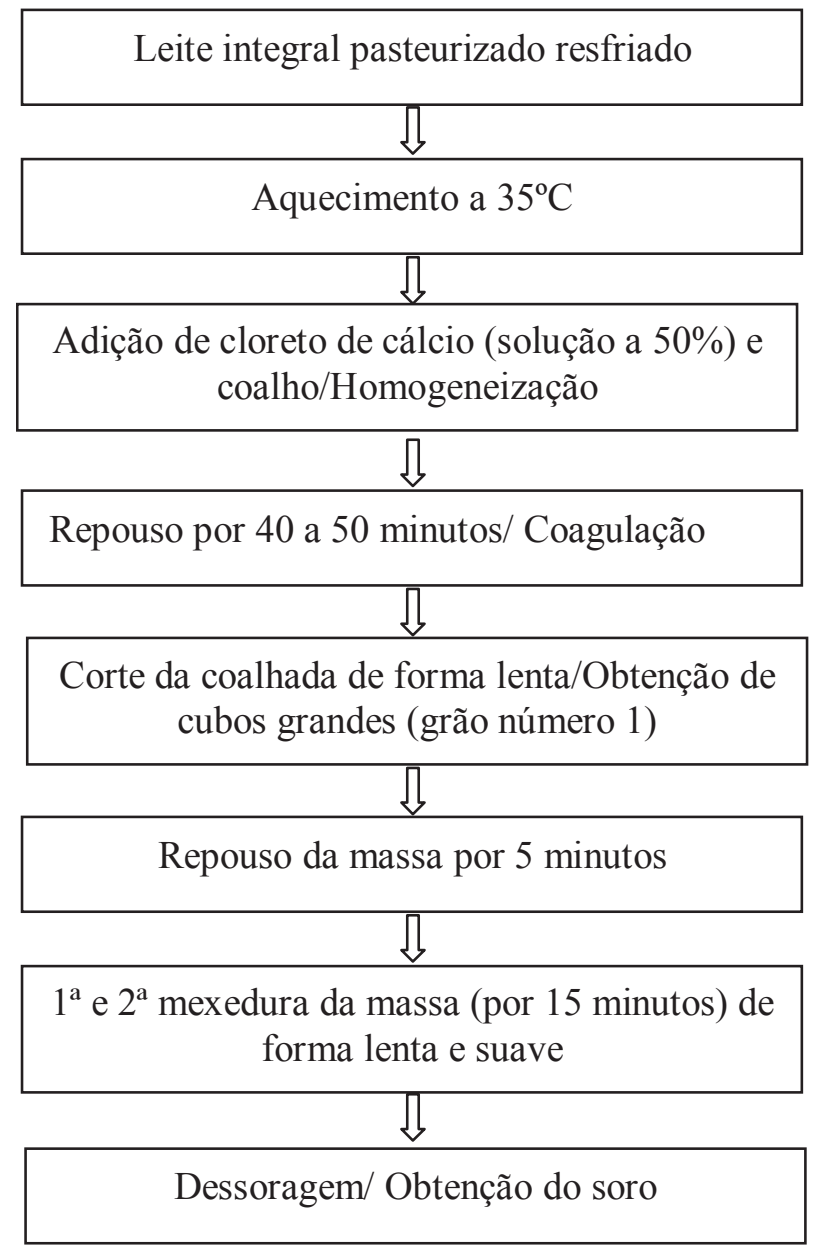

Fonte: Elaboração dos autores. 
Formulação das bebidas lácteas fermentadas

Foi utilizado o delineamento experimental inteiramente casualizado, com três repetições, em experimento fatorial $5 \times 2$, sendo cinco diferentes tipos de estabilizantes/espessantes e duas proporções. Dez tratamentos de bebida láctea fermentada (T1; T2; T3; T4; T5; T6; T7; T8; T9 e T10) constituídos de leite pasteurizado (50\%), soro de queijo (50\%), cultura lática (cultivo lácteo de inoculação direta, Sacco® Lyofast Y450 B, constituído por cepas de Streptococcus salivarius ssp. thermophilus e Lactobacillus delbrueckii ssp. Bulgaricus com dosagem de cinco unidades de coagulação (5UC) para $500 \mathrm{~L}$ de leite e sacarose (10\%) foram preparados com cinco diferentes tipos de estabilizantes/espessantes nas concentrações de 0,50 e $1,00 \%(\mathrm{p} / \mathrm{v})$. Em nenhum dos tratamentos foi acrescentado conservantes, corantes, polpas, ou aromatizantes (Tabela 1).

Tabela 1. Proporções dos diferentes estabilizantes/espessantes utilizados na elaboração das bebidas lácteas.

\begin{tabular}{lcccccc}
\hline \multicolumn{1}{c}{ Tratamentos } & PCPS (\%) & GP(\%) & GG (\%) & AM (\%) & $\begin{array}{c}\text { GGCMC } \\
(\%)\end{array}$ & $\begin{array}{c}\text { \% das } \\
\text { combinaçóes }\end{array}$ \\
\hline T1 = PCPS 1,00\% & 1,00 & & & & & 1,00 \\
T2 = GP 1,00\% & & 1,00 & & & & 1,00 \\
T3 = GG 1,00\% & & 1,00 & & & 1,00 \\
T4 = AM 1,00\% & & & 1,00 & & 1,00 \\
T5 = GGCMC 1,00\% & & & & & 1,00 & 1,00 \\
T6 = PCPS 0,50\% & 0,50 & & & & 0,50 \\
T7 = GP 0,50\% & & & & & 0,50 \\
T8 = GG 0,50\% & & 0,50 & & & 0,50 \\
T9 = AM 0,50\% & & & 0,50 & & 0,50 \\
T10 = GGCMC 0,50\% & & & & 0,50 & 0,50 \\
\hline
\end{tabular}

Legenda: T1: PCPS $1,00 \%=$ proteína $(0,50 \%)$ e concentrado proteico de soro $(0,50 \%)$; T2: GP $1,00 \%=$ gelatina em pó, incolor, sem sabor (1,00\%); T3: GG 1,00\% = goma guar (1,00\%); T4: AM 1,00\% = amido de milho $(1,00 \%)$; T5: GGCMC $1,00 \%=$ goma guar $(0,50 \%)$ e carboximetilcelulose $(0,50 \%)$; T6: PCPS $0,50 \%=$ proteína $(0,25 \%)$ e concentrado proteico de soro $(0,25 \%)$; T7: GP $0,50 \%=$ gelatina em pó $(0,50 \%)$; T8: GG $0,50 \%=$ goma guar $(0,50 \%)$; T9: AM $0,50 \%=$ amido de milho $(0,50 \%)$; T10: GGCMC $0,50 \%$ = goma guar $(0,25 \%)$ e carboximetilcelulose $(0,25 \%)$

Fonte: Elaboração dos autores.

\section{Processamento das bebidas lácteas fermentadas}

O processamento das bebidas lácteas fermentadas foi baseado na metodologia descrita por Santos et al. (2008), com algumas modificações (Figura 2). Posteriormente à mistura de leite e soro, foram adicionados sacarose e estabilizante/espessante. A mistura foi pasteurizada a $65^{\circ} \mathrm{C}$ por 30 minutos e resfriada até $43{ }^{\circ} \mathrm{C}$, sendo adicionado $6 \mathrm{ml} . \mathrm{L}^{-1}$ do cultivo lácteo de inoculação direta, Sacco® Lyofast Y450 B constituído por cepas de Streptococcus salivarius ssp. thermophilus e Lactobacillus delbrueckii ssp. Bulgaricus com dosagem de 5UC para 500L de leite. O cultivo lácteo foi dissolvido em $1 \mathrm{~L}$ de leite pasteurizado e ocorreu a adição de $6 \mathrm{~mL}$ do inóculo para cada litro da mistura (leite e soro). Em seguida, foi realizada homogeneização e incubação a $43^{\circ} \mathrm{C}$ por um período médio de cinco horas. A fermentação da bebida láctea ocorreu até o $\mathrm{pH}$ do meio atingir valores de 4,0 $( \pm 0,25)$. Este intervalo de $\mathrm{pH}$ foi determinado considerando as características sensoriais e de conservação do produto. Após a fermentação, a bebida láctea foi acondicionada em potes transparentes de polietileno com capacidade de $1 \mathrm{~L}$ fechados após envase e mantida sob refrigeração à temperatura de $4 \pm 1^{\circ} \mathrm{C}$, por 12 horas, sendo o coágulo quebrado por meio 
de agitação manual ao término desse período. polietileno $(1 \mathrm{~L} \mathrm{e} 140 \mathrm{~mL})$ e armazenadas a $4 \pm 1^{\circ} \mathrm{C}$, Depois de prontas, as bebidas lácteas fermentadas até o momento da realização das análises (entre 7 e foram acondicionadas em garrafas transparentes de 15 dias de armazenamento).

Figura 2. Fluxograma de elaboração de bebida láctea fermentada.

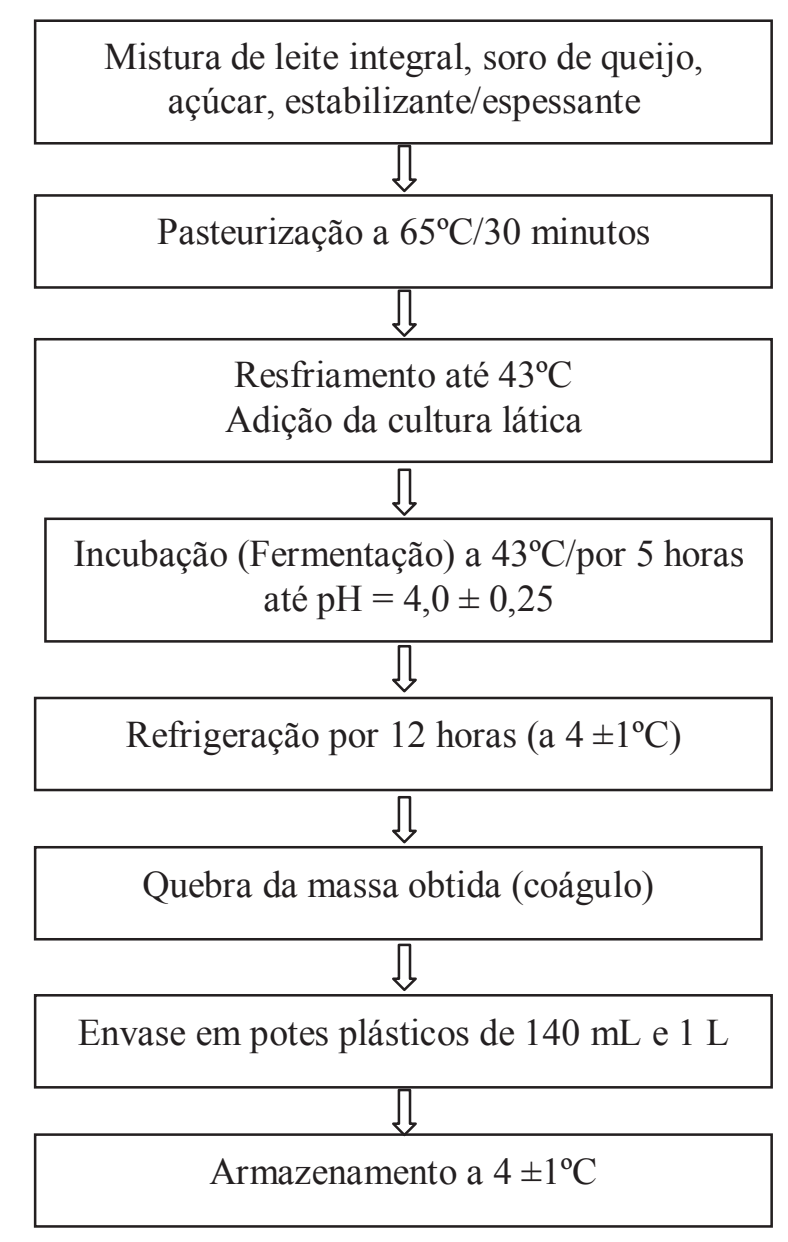

Fonte: Elaboração dos autores.

\section{Avaliação das bebidas lácteas fermentadas}

Em todos os tratamentos foram realizados as análises físico-químicas ( $\mathrm{pH}$, acidez titulável, viscosidade a $30 \mathrm{rpm}$, viscosidade a $60 \mathrm{rpm}$ e sinérese) no sétimo dia de armazenamento e microbiológicas (coliformes a $35^{\circ} \mathrm{C}$ e a $45^{\circ} \mathrm{C}$ ) entre 7 e 15 dias de armazenamento.

Os tratamentos que após o processamento apresentaram visualmente viscosidade aparente/ consistência mais firme (similiar/compatível com iogurtes e bebidas lácteas fermentadas existentes no mercado) e ausência de sinérese (no sétimo dia de armazenamento) foram submetidos às análises físico-químicas (umidade, cinzas, lipídios e proteínas) e teste de aceitação sensorial (atributos aparência, aroma, cor e textura) realizadas entre $7 \mathrm{e}$ 15 dias de armazenamento.

Todas as determinações físico-químicas e microbiológicas foram realizadas em triplicata. 
Avaliações físico-químicas das bebidas lácteas fermentadas

As análises de umidade, cinzas, lipídios, proteína total, $\mathrm{pH}$, acidez titulável foram realizadas segundo Brasil (2006). A umidade foi determinada pelo método gravimétrico com emprego de calor, em que se determinou a perda de peso do material quando submetido ao aquecimento $\left(105^{\circ} \mathrm{C}\right)$ até obtenção de peso constante. As cinzas foram determinadas gravimetricamente por incineração em forno mufla a $550^{\circ} \mathrm{C}$. Os lipídios foram determinados gravimetricamente após extração em frascos de Mojonnier. A proteína total foi determinada pelo método micro-Kjeldahl, utilizando o fator de conversão de nitrogênio para proteína igual a 6,38. $\mathrm{O} \mathrm{pH}$ foi determinado utilizando-se potenciômetro previamente calibrado, introduzindo-se o eletrodo diretamente na amostra homogênea. A acidez titulável foi determinada através de titulação da amostra com hidróxido de sódio N/9 em presença do indicador fenolftaleína e os resultados foram expressos em porcentagem de ácido lático.

A sinérese espontânea foi determinada pela metodologia descrita por Fiszman, Lluch e Salvador (1999), através da coleta do soro liberado de forma espontânea do produto, o qual permaneceu em seu recipiente de fermentação até realização da análise. O soro acumulado na superfície do produto foi retirado com auxílio de uma seringa. A determinação de sinérese ocorreu no tempo máximo de dois minutos de exposição das amostras à temperatura ambiente. A sinérese foi expressa em gramas de soro por 100 gramas do produto. O índice de sinérese foi calculado, através da equação: [(peso do soro após filtração / peso da amostra) $\mathrm{x}$ 100] (RIENER et al., 2010). Para determinação da viscosidade aparente, as amostras de bebida láctea fermentada foram homogeneizadas e, em seguida cerca de $500 \mathrm{~mL}$ foram vertidos para um béquer para conduzir a análise. Foi utilizado viscosímetro digital programável BROOKFIELD, Modelo DV-II + com spindle (sonda cilíndrica) S63 acoplado, durante um período de 30 segundos, sob velocidade de 30 e 60 rotações por minuto (rpm) e temperatura de $6 \pm 1{ }^{\circ} \mathrm{C}$, sendo registrados os valores em centipoise $(\mathrm{cP})$, (KOKSOY; KILIC, 2004; CALDEIRA et al., 2010).

\section{Análises microbiológicas das bebidas lácteas} fermentadas

As determinações microbiológicas foram efetuadas de acordo com metodologia descrita por Brasil (2003), em que se avaliou a presença de coliformes totais $\left(35^{\circ} \mathrm{C}\right)$ e coliformes termotolerantes $\left(45^{\circ} \mathrm{C}\right)$, segundo os parâmetros microbiológicos preconizados pela legislação para bebidas lácteas fermentadas (BRASIL, 2005).

\section{Avaliação sensorial das bebidas lácteas fermentadas}

Foi avaliada a aceitação empregando-se escala hedônica estruturada de 9 pontos ancorada com termos verbais nos extremos "desgostei muitíssimo" (1) e gostei muitíssimo (9) (STONE; SIDEL, 2004). Cinquenta julgadores não-treinados avaliaram a aceitação quanto a aparência, aroma, cor e textura das bebida em cabines individuais, iluminadas com luz branca. Os procedimentos e as condições ambientais da análise sensorial seguiram as recomendações de Minim (2010). As amostras, oferecidas em recipientes descartáveis de cor branca dotados de suportes codificados com três dígitos numéricos, foram apresentadas de forma monádica e avaliadas à temperatura de refrigeração. $\mathrm{O}$ procedimento de pesquisa foi aprovado pelo Comitê de Ética em Pesquisa/UFG, protocolo $\mathrm{n}^{\circ}$ 038/12.

O Índice de Aceitabilidade (IA) foi calculado considerando-se a nota máxima alcançada, pelo produto analisado como $100 \%$ e a pontuação média, em \%, como IA (TEIXEIRA; MEINERT; BARBETTA, 1987) (equação 1). Produtos com IA igual ou superior a $70 \%$ foram considerados como aceitos (MONTEIRO, 1984; TEIXEIRA; MEINERT; BARBETTA, 1987; DUTCOSKY, 1996). 


\section{$\mathrm{IA}(\%)=\mathrm{A} \times 100 / \mathrm{B} \quad$ (equação 1)}

em que $\mathrm{A}=$ nota média obtida para o produto e $\mathrm{B}=$ nota máxima dada ao produto.

\section{Análise estatística}

Os resultados sensoriais e físico-químicos foram submetidos à análise de variância (ANOVA) e as diferenças das médias comparadas por teste de Tukey ao nível de 5\% de significância, utilizandose o software R versão 2.11.1 (R DEVELOPMENT CORE TEAM, 2010).

\section{Resultados e Discussão}

Caracterização físico-química das bebidas lácteas fermentadas

Os resultados das análises físico-químicas de acidez, $\mathrm{pH}$, viscosidade e sinérese após o sétimo dia de armazenamento, estão descritos na Tabela 2.

Os tratamentos GP $(1,00 \%$ e $0,50 \%)$ apresentaram os maiores valores absolutos de acidez e o tratamento GGCMC (1,00\%) apresentou menor valor (Tabela 2). Os valores de acidez obtidos nos tratamentos variaram na faixa de $0,55 \%$ a $0,61 \%$ de ácido lático e são inferiores aos valores comuns informados por Souza (1991) para iogurte (0,7 a 1,25\% de ácido láctico ou pH de 3,7 a 4,6), pois este tipo de produto (bebida láctea fermentada) caracteriza-se por apresentar acidez mais elevada e metabólitos produzidos por bactérias ácido-lácticas que inibem o crescimento de microrganismos indesejáveis e os iogurtes comumente possuem acidez menor. Segundo o mesmo autor, o teor de sólidos do leite exerce grande influência na acidez titulável, sendo o $\mathrm{pH}$ o melhor critério para se expressar a acidez do iogurte. Apesar de não existir legislação federal específicando valores $\mathrm{pH}$ e acidez para bebida láctea fermentada, verificou-se que a acidez observada nos tratamentos atende ao valor mínimo estabelecido para iogurte $(0,6$ a $1,5 \mathrm{~g}$ de ácido lático/100 g) e leite fermentado $(0,6$ a 2,0 g de ácido lático/100 g) preconizado no Regulamento Técnico de Identidade e Qualidade (RTIQ) de Leites Fermentados (BRASIL, 2007).

Os tratamentos T4 $(3,98)$, T5 $(3,95)$ e T10 $(3,96)$ apresentaram os menores valores de $\mathrm{pH}$, enquanto os tratamentos T6 $(4,07)$ e T7 $(4,07)$ apresentaram os maiores valores $(p<0,05)$. Os demais tratamentos (T1, T2, T3, T8 e T9) não diferiram significativamente $(\mathrm{p}<0,05)$ entre si e dos tratamentos T4, T5, T6, T7 e T10 (Tabela 2). Santos et al. (2008), avaliando a influência da concentração de soro na aceitação de bebida láctea fermentada com polpa de manga utilizando soro de queijo nas concentrações de $40 \%$ e $60 \%$, obtiveram resultados de $\mathrm{pH}$ respectivamente, de 3,83 $\pm 0,28 \mathrm{e}$ $3,73 \pm 0,33$, similares aos encontrados neste estudo ( $\mathrm{pH}$ entre 3,95 e 4,07). Provavelmente isto ocorreu devido ao $\mathrm{pH}$ baixo e acidez elevada da polpa de manga (pH mínimo de 3,30 e acidez total expressa em ácido cítrico no mínimo de 0,32 estabelecido em Brasil (2000)). Os resultados de $\mathrm{pH}$ (entre 3,95 e 4,07) obtidos neste estudo encontram-se dentro dos valores usuais para iogurtes $(3,7$ a 4,6) (SOUZA, 1991). A lactose, componente presente em maior porcentagem na porção sólida do soro lácteo, provavelmente, é responsável pelos valores de $\mathrm{pH}$ deste estudo, pois este carboidrato durante a fermentação produz ácido lático. Além disso, sabe-se que no início da fermentação o $\mathrm{pH}$ do leite favorece o desenvolvimento de Streptococcus salivarius subspécie thermophilus o qual tende a ser inibido quando o $\mathrm{pH}$ atinge valores de 4,2 a 4,4. Entretanto com o aumento da acidificação, ou seja, do teor de ácido láctico, crescem os Lactobacillus delbrueckii subspécie bulgaricus que podem tolerar valores de $\mathrm{pH}$ na faixa de 3,5 a 3,8 (ANDRADE, 2010). A utilização dos diferentes cultivos bacterianos iniciadores, a adição de soro, a composição do leite, o processamento, incluindo as etapas pós-fermentação, como por exemplo a quebra do coágulo e a temperatura de armazenagem, podem modificar os valores de $\mathrm{pH}$ dos produtos lácteos (MENEZES, 2011). Na literatura são 
descritos para bebida láctea fermentada $\mathrm{pH}$ entre 4,0 e 4,5 e acidez entre 0,5 e 0,7\% de ácido lático (ALMEIDA; BONASSI; ROÇA, 2001; OLIVEIRA et al., 2006; SANTOS et al., 2006; SANTOS et al., 2008; GOMES; PENNA, 2009; MATOS, 2009; ANDRADE, 2010; MENEZES, 2011).

Quanto à viscosidade avaliada a $30 \mathrm{rpm}$, a amostra com $1 \%$ de gelatina apresentou o maior valor $(1142,00 \mathrm{cP})$. Os menores valores foram observados para as amostras adicionadas de GGCMC a $1,00 \%(112,00 \mathrm{cP})$ e PCPS a $0,50 \%$ $(125,33 \mathrm{cP})$ foram iguais entre $\mathrm{si}(\mathrm{p}<0,05)$. Contudo observou-se visualmente e através dos valores de viscosidade que os tratamentos com 1,00 e $0,50 \%$ de gelatina apresentaram viscosidade/consistência diferentes, ou seja, a amostra GP a 1,00\% com consistência e firmeza semelhantes ao de uma sobremesa láctea (tipo pudim), enquanto a amostra GP a $0,50 \%$ com a consistência próxima à de iogurte e bebida láctea. Keogh e O'Kennedy (1998) estudaram as propriedades reológicas do iogurte com diferentes hidrocolóides e também verificaram aumento de consistência com o uso de gelatina, mas não com amido. Fiszman, Lluch e Salvador (1999), utilizaram gelatina para estudar as propriedades reológicas de iogurte e leite fermentado e avaliaram o efeito da gelatina sobre os parâmetros de penetração (firmeza, deslocamento e índice de rigidez do gel) e sinérese dos géis (drenagem de soro de queijo), observaram de forma similar, que as diferenças nas propriedades de firmeza e da retenção de água poderiam ser atribuídas à natureza da composição (da microestrutura) das várias amostras (iogurte e leite fermentado com e sem adição de gelatina e de sólidos do leite), em que as amostras adicionadas de gelatina apresentaram maior firmeza e índice de rigidez do gel.

Em relação à viscosidade à 60 rotações por minuto (60 rpm), o produto adicionado de goma guar $(1,00 \%)$ apresentou o maior valor $(1274,93 \mathrm{cP})$. Os tratamentos PCPS a $0,50 \%(100,00 \mathrm{cP})$, GGCMC a $1,00 \%(114,67 \mathrm{cP})$ e GGCMC a $0,50 \%(159,33 \mathrm{cP})$ não diferiram entre si $(\mathrm{p}<0,05)$ e apresentaram os menores valores (Tabela 2). Koksoy e Kilic (2004) estudaram o uso de hidrocolóides para prevenir a separação de soro durante armazenamento na estabilização da textura de uma bebida de iogurte, ayran, em que a consistência firme (elevada viscosidade) e sem separação de soro são características desejadas. Pectina com alto grau de metoxilação, goma guar, goma de alfarroba e gelatina em diferentes concentrações foram adicionadas as bebidas e as amostras foram avaliadas durante a armazenagem por 15 dias a $4^{\circ} \mathrm{C}$. Segundo os autores, o uso de goma guar, proporcionou uma maior viscosidade aparente e índice de consistência e impediu separação do soro em ayran, sendo similar ao tratamento adicionado de GG a 1,00\%. Segundo WEBER (2005), a goma guar, é muito utilizada em aplicações onde é necessário espessamento, estabilização, controle de viscosidade, suspensão e formação de corpo, modificação de textura e consistência e retenção de água. Segundo Janhøj, Frøst e Ipsen (2008), estudando a caracterização sensorial e reológica de bebidas lácteas acidificadas, verificaram que as bebidas de iogurte estabilizadas com pectina e carboximetilcelulose (CMC) a $0,3 \%$ e $0,5 \%$ mostraram resultados de viscosidade superiores para o uso do estabilizante a $0,5 \%$, destacando valores de viscosidade superior com o uso de CMC a $0,5 \%$, diferente dos resultados obtidos no presente estudo para as formulações T5 e T10. CMC, hidrocolóide aniônico, é conhecida por interagir com micelas de caseína formando complexos solúveis com a proteína do leite a um $\mathrm{pH}$ baixo e aumentando a viscosidade, sem interferir na ordenação da estrutura. Os resultados de viscosidade indicam que os agregados de proteína do leite são estabilizados por CMC e não interagiram extensivamente com a goma guar a 0,50 e $1,00 \%$. As razões da baixa viscosidade dos produtos lácteos parecem ser as diferentes propriedades funcionais e o modo de interação com proteínas do leite entre a goma guar e CMC, as quais influenciam as propriedades reológicas de diferentes maneiras (JANHØJ; FRØST; IPSEN, 2008). 
Tabela 2. Valores de acidez, pH, viscosidade e sinérese das amostras de bebida láctea fermentada resultantes de dez tratamentos com diferentes proporções de estabilizantes/espessantes, após sete dias de estocagem.

\begin{tabular}{|c|c|c|c|c|c|}
\hline \multirow[b]{2}{*}{ Tratamentos } & \multicolumn{5}{|c|}{ Características } \\
\hline & $\begin{array}{c}\text { Acidez } \\
\text { (\% ác. lático) }\end{array}$ & pH & $\begin{array}{c}\text { Viscosidade } \\
\text { a } 30 \mathrm{rpm}(\mathrm{cP})\end{array}$ & $\begin{array}{c}\text { Viscosidade } \\
\text { a } 60 \mathrm{rpm}(\mathrm{cP})\end{array}$ & $\begin{array}{l}\text { Sinérese } \\
(\%)\end{array}$ \\
\hline $\mathrm{T} 1=$ PCPS $1,00 \%$ & $0,59 \pm 0,00^{\mathrm{abc}}$ & $4,03 \pm 0,01^{\mathrm{ab}}$ & $397,33 \pm 0,02^{\mathrm{d}}$ & $309,33 \pm 0,01^{\mathrm{de}}$ & $0,00 \pm 0,00^{\mathrm{e}}$ \\
\hline $\mathrm{T} 2=\mathrm{GP} 1,00 \%$ & $0,61 \pm 0,01^{\mathrm{a}}$ & $4,02 \pm 0,04^{\mathrm{ab}}$ & $1142,00 \pm 0,30^{\mathrm{a}}$ & $806,67 \pm 0,83^{\mathrm{b}}$ & $0,00 \pm 0,00^{\mathrm{e}}$ \\
\hline $\mathrm{T} 3=\mathrm{GG} 1,00 \%$ & $0,57 \pm 0,01 b^{\text {cd }}$ & $4,00 \pm 0,05^{\mathrm{ab}}$ & $202,80 \pm 0,71^{\mathrm{ef}}$ & $1274,93 \pm 0,56^{\mathrm{a}}$ & $0,00 \pm 0,00^{\mathrm{e}}$ \\
\hline $\mathrm{T} 4=\mathrm{AM} 1,00 \%$ & $0,58 \pm 0,00 \mathrm{~b}^{\mathrm{cd}}$ & $3,98 \pm 0,02^{\mathrm{b}}$ & $934,67 \pm 0,63^{\mathrm{b}}$ & $630,00 \pm 0,01^{\mathrm{c}}$ & $37,81 \pm 0,78^{\mathrm{d}}$ \\
\hline $\mathrm{T} 5=\mathrm{GGCMC} 1,00 \%$ & $0,55 \pm 0,01^{\mathrm{d}}$ & $3,95 \pm 0,02^{\mathrm{b}}$ & $112,00 \pm 0,58^{\mathrm{g}}$ & $114,67 \pm 0,14^{\mathrm{fg}}$ & $82,52 \pm 0,27^{\mathrm{a}}$ \\
\hline $\mathrm{T} 6=\mathrm{PCPS} 0,50 \%$ & $0,57 \pm 0,00 \mathrm{~b}^{\mathrm{cd}}$ & $4,07 \pm 0,04^{\mathrm{a}}$ & $125,33 \pm 0,24 \mathrm{f}^{\mathrm{g}}$ & $100,00 \pm 0,10^{\mathrm{g}}$ & $33,13 \pm 0,01^{\mathrm{d}}$ \\
\hline $\mathrm{T} 7=\mathrm{GP} 0,50 \%$ & $0,61 \pm 0,01^{\mathrm{a}}$ & $4,07 \pm 0,03^{\mathrm{a}}$ & $537,33 \pm 0,09^{c}$ & $402,00 \pm 0,60^{\mathrm{d}}$ & $0,00 \pm 0,00^{\mathrm{e}}$ \\
\hline $\mathrm{T} 8=\mathrm{GG} 0,50 \%$ & $0,57 \pm 0,00^{\text {cd }}$ & $4,01 \pm 0,03^{\mathrm{ab}}$ & $277,33 \pm 0,63^{\mathrm{e}}$ & $216,67 \pm 0,08^{\mathrm{ef}}$ & $82,33 \pm 0,56^{\mathrm{a}}$ \\
\hline $\mathrm{T} 9=\mathrm{AM} 0,50 \%$ & $0,60 \pm 0,01^{\mathrm{ab}}$ & $4,00 \pm 0,03^{\mathrm{ab}}$ & $541,33 \pm 0,12^{\mathrm{c}}$ & $370,00 \pm 0,10^{\mathrm{d}}$ & $47,89 \pm 0,57^{\mathrm{c}}$ \\
\hline $\mathrm{T} 10=$ GGCMC $0,50 \%$ & $0,57 \pm 0,01^{\mathrm{cd}}$ & $3,96 \pm 0,02^{\mathrm{b}}$ & $220,00 \pm 0,08^{\mathrm{e}}$ & $159,33 \pm 0,14^{\mathrm{fg}}$ & $63,99 \pm 0,40^{\mathrm{b}}$ \\
\hline
\end{tabular}

Médias na mesma coluna e com letras iguais não diferem significativamente entre si pelo teste de Tukey $(p<0,05)$. Os valores correspondem à média de três repetições com estimativa do desvio padrão.

Fonte: Elaboração dos autores.

Em relação ao percentual de sinérese (Tabela 2) observou-se que os tratamentos PCPS a $1,00 \%$, GP a $1,00 \%$, GG a $1,00 \%$ e GP a $0,50 \%$ diferenciaramse dos demais $(\mathrm{p}<0,05)$ pela ausência de sinérese. Rossi, Reddy e Silva (1984) observaram menor corpo do "iogurte de soja" em relação aos dos iogurtes tradicionais, mesmo com a adição de sólidos de leite desengordurados e gelatina como estabilizantes/espessantes na concentração máxima de até $0,5 \%$. De acordo com os mesmos autores, após sete dias de estocagem refrigerada, o produto apresentava nítidos sinais de sinérese. O tratamento adicionado de $0,50 \%$ gelatina não apresentou os mesmos resultados físico-químicos observados pelos autores acima, provavelmente, em razão das diferentes forças de bloom de gelatina empregados. Os tratamentos T2 (gelatina 1,00\%) e T7 (gelatina 0,50\%) foram mais efetivas com relação à sinérese, independente da concentração usada. Esses resultados estão de acordo com os encontrados por Jawalekar et al. (1993) que, ao avaliarem formulações de iogurte a base de leite de vaca e de búfala, usando gelatina como estabilizantes/espessantes, demonstraram bons resultados para os testes de consistência e sinérese, ou seja, comprovaram a eficiência da gelatina na retenção de água com redução da sinérese. Keogh e O'Kennedy (1998) utilizaram concentrações variadas de gelatina no iogurte $(0,0$ a $0,5 \%)$ e verificaram redução de sinérese na concentração máxima de $0,5 \%$, corroborando com os resultados obtidos no tratamento adicionado de GP a 0,50\%. Fiszman, Lluch e Salvador (1999) avaliaram o efeito da adição de gelatina na microestrutura dos géis de iogurte e leite fermentado e nas propriedades reológicas, observando ausência de sinérese para as amostras com gelatina, devido à capacidade de retenção de água da gelatina. Segundo os autores os resultados revelaram diferenças microestruturais significativas entre o iogurte elaborado com e sem gelatina em dois níveis de sólidos totais do leite, demonstrando a aptidão da utilização de gelatina para melhorar a qualidade dos produtos lácteos. Resultados similares foram obtidos no presente trabalho para os tratamentos com gelatina a 1,00\% e $0,50 \%$, ambos apresentaram ausência de sinérese. Koksoy e Kilic (2004) mencionaram que o uso de gelatina não impediu a separação do soro em ayran em um nível de $0,25 \%$, mas foi eficaz em um aumento da concentração de $0,50 \%$, similar ao tratamento adicionado de GP a 0,50\%. Em laticínios, como na fabricação de iogurte e queijos 
processados, a goma guar fornece uma textura macia e reduz a sinérese (WEBER, 2005). Supavititpatana et al. (2008), estudando a adição de gelatina reforçando a gelificação do iogurte de "leite" de milho, com uma combinação de caseinato de sódio mais gelatina $(0,0 ; 0,2 ; 0,4$ e $0,6 \%)$ e determinando qualidade dos géis por medição de acidez, sinérese e perfil de textura, constataram que a adição de uma gelatina comercial em $0,4 \%$ ocasionou boa aceitabilidade para o produto, com pouca sinérese dos géis produzidos. Os autores citaram que uma gelatina comercial com diferente especificação/ força do bloom pode exigir concentração diferente para ser eficaz. Segundo Manzano et al. (2008), quando se trata de iogurte, a textura e o corpo são tão importantes quanto o próprio sabor. Firmeza adequada e ausência de sinérese são essenciais para se obter um produto de alta qualidade, e a gelatina e as gomas utilizadas como estabilizantes/espessantes em iogurtes convencionais conferem a eles melhor consistência e redução da sinérese. Os autores observaram que produtos processados apenas com a gelatina apresentaram maior consistência, menor sinérese e maior capacidade de retenção de água, de forma similar ao que ocorreu no presente estudo, referente aos tratamentos com 1,00 e $0,50 \%$ de gelatina (Tabela 2).

Os tratamentos adicionados de GGCMC a $1,00 \%$ $(82,52 \%)$ e $\mathrm{GG}$ a $0,50 \%(82,33 \%)$ apresentaram os maiores percentuais de sinérese $(\mathrm{p}<0,05)$ (Tabela 2), seguidos das amostras GGCMC a $0,50 \%$ $(63,99 \%)$, AM a $0,50 \%(47,89 \%)$, AM a $1,00 \%$ $(37,81 \%)$ e PCPS a $0,50 \%(33,13 \%)$. Considerandose as diferenças estruturais e reológicas do comportamento das soluções de CMC e de amido, seria de esperar que ambos os espessantes afetam as características físicas de emulsões de forma diferente (ARANCIBIA et al., 2011). A goma guar não forma gel, sendo compatível com outras gomas, amidos, hidrocolóides e agentes gelificantes (naturais e sintéticos) e quando adicionada em mistura com polissacarídeos geleificantes, pode aumentar a força do gel e modificar sua estrutura
(DZIEZAK,1991; SANDERSON, 1996). A CMC tem algumas limitações em aplicações específicas, em que a sua utilização é recomendada em meio de $\mathrm{pH}$ acima de 4,2, se a fermentação do produto progride abaixo deste nível de $\mathrm{pH}$, a separação de fases pode ocorrer (GALLARDO-ESCAMILLA; KELLY; DELAHUNTY, 2007), conforme foi observado neste estudo com percentuais elevados de sinérese nas amostras adicionadas de GGCMC a 0,50 e $1,00 \%$ (Tabela 2).

Os tratamentos com PCPS a 1,00\%, GG a $1,00 \%$ e GP a $0,50 \%$ que apresentaram viscosidade/ consistência similiar/compatível com bebidas lácteas fermentadas e não apresentaram sinérese após processamento (Tabela 2), foram selecionados e nestes realizaram-se (entre 7 e 15 dias de armazenamento) as análises de umidade, cinzas, lipídeos, proteínas (Tabela 3) e aceitação sensorial (Tabelas 5 e 6), diferente do tratamento com gelatina a 1\% que apesar da ausência de sínerese apresentou consistência muito firme (semelhante a pudim).

Com relação ao percentual de umidade não houve diferença significativa $(p<0,05)$ entre os tratamentos (Tabela 3). Thamer e Penna (2006) em seus estudos encontraram entre $17,07 \%$ e $17,57 \%$ de sólidos totais $(82,42 \%$ a $82,93 \%$ de umidade) nos tratamentos com $50 \%$ de soro, resultados estes de umidade superiores aos dos tratamentos T1, T3 e T7. Esta diferença de umidade deu-se ao fato dos tratamentos T1, T3 e T7 terem sido elaborados com leite integral e possuírem assim maior teor de sólidos totais, principalmente devido ao conteúdo de lipídios e carboidratos. Quanto aos valores de cinzas os tratamentos $\mathrm{T} 1(0,59 \%)$ e $\mathrm{T} 7$ $(0,62 \%)$ foram significativamente iguais entre si $(\mathrm{p}<0,05)$ e apresentaram os maiores valores quando comparados com o tratamento T3 $(0,52 \%)$. Estes resultados foram similares aos dados de cinzas $(0,53$ a $0,58 \%)$, encontrados por Thamer e Penna (2006) nos tratamentos com $50 \%$ de soro lácteo, em que estudaram a caracterização de bebidas lácteas funcionais fermentadas por probióticos e acrescidas de prebiótico. Em relação ao conteúdo de lipídios 
os tratamentos $\mathrm{T} 1(1,63 \%)$ e $\mathrm{T} 7(1,47 \%)$ foram significativamente diferentes entre si $(p<0,05)$ e o tratamento $\mathrm{T} 7$ (com $0,5 \%$ de gelatina) apresentou o menor valor quando comparado com o tratamento T1. O tratamento T3 não diferiu significativamente $(\mathrm{p}<0,05)$ dos tratamentos T1 e T7 quanto ao conteúdo de lipídios. Os resultados de lipídios mostrados anteriormente foram superiores aos dados $(0,00$ a $0,10 \%)$ encontrados por Thamer e Penna (2006) nos tratamentos com $50 \%$ de soro lácteo. Esta diferença ocorreu devido a Thamer e Penna (2006) terem utilizado leite em pó desnatado na elaboração das bebidas lácteas e os tratamentos da presente pesquisa foram fabricados com leite pasteurizado integral. O Regulamento Técnico de Identidade e Qualidade (RTIQ) de Bebida Láctea (BRASIL, 2005) não estabelece padrão para o teor de gordura de bebidas lácteas fermentadas. No entanto, muitos consumidores estão modificando seus hábitos alimentares em função da saúde e preferindo alimentos com redução na quantidade de gordura. Observou-se que os valores de lipídios obtidos são menores que os encontrados para leite, pois a bebida láctea é caracterizada pela mistura de leite e soro lácteo, e este último ingrediente apresenta reduzido teor de gordura em relação ao primeiro (ANDRADE, 2010). Sobre os percentuais de proteínas os tratamentos T3 (2,21\%) e T7 (2,58\%) foram significativamente diferentes entre si $(p<0,05)$ e o tratamento T3 apresentou o menor valor quando comparada com o tratamento $\mathrm{T} 7$. O tratamento T1 não diferiu significativamente $(p<0,05)$ dos tratamentos T3 e T7 quanto ao percentual de proteínas. Entretanto os tratamentos T1, T3 e T7 possuem conteúdo de proteína $(2,46 \% ; 2,21 \%$ e $2,58 \%$ ) superior a $1,0 \mathrm{~g} / 100 \mathrm{~g}$ estando, desta forma, dentro dos padrões recomendados pela legislação (BRASIL, 2005) para bebida láctea fermentada com adição. As bebidas lácteas fermentadas elaboradas se enquadram neste padrão de identidade e qualidade, podendo, portanto, receberem esta denominação e serem comercializadas como tal. Para bebidas lácteas fermentadas o teor mínimo de proteínas lácteas no produto final é de $1,0 \%(\mathrm{~m} / \mathrm{m})$ para o produto adicionado de leite fermentado, produto ou substância (s) alimentícia (s) e de 1,7\% (m/m) para os produtos sem adição de leite fermentado, produto ou substância (s) alimentícia (s) (BRASIL, 2005). Os resultados de proteínas $(2,18 \%$ e $2,46 \%)$, obtidos respectivamente em amostras de bebida láctea fermentada com adição de $50 \%$ e $45 \%$ de soro, através dos estudos de Thamer e Penna (2006), foram similares aos encontrados nesta pesquisa $(2,46 \% ; 2,21 \%$ e $2,58 \%)$. Observou-se que a adição dos estabilizantes/espessantes a base de proteína e concentrado proteico de soro $(1,00 \%)$, goma guar $(1,00 \%)$ e gelatina $(0,50 \%)$, em função de sua composição tiveram influência nos resultados dos percentuais de proteínas obtidos nos tratamentos.

Tabela 3. Valores médios de umidade, cinzas, lipídios e proteínas das amostras de bebida láctea fermentada resultantes de três tratamentos com diferentes proporções de estabilizantes/espessantes.

\begin{tabular}{|c|c|c|c|c|}
\hline \multirow{2}{*}{ Tratamentos } & \multicolumn{4}{|c|}{ Características } \\
\hline & Umidade $(\% \mathrm{~m} / \mathrm{m})$ & Cinzas $(\% \mathrm{~m} / \mathrm{m})$ & Lipídios (\% m/m) & Proteínas $(\% \mathrm{~m} / \mathrm{m})$ \\
\hline $\mathrm{T} 1=$ PCPS $1,00 \%$ & $80,42 \pm 0,76^{\mathrm{a}}$ & $0,59 \pm 0,02^{a}$ & $1,63 \pm 0,06^{\mathrm{a}}$ & $2,46 \pm 0,12$ \\
\hline $\mathrm{T} 3=$ GG $1,00 \%$ & $80,25 \pm 0,06^{\mathrm{a}}$ & $0,52 \pm 0,00^{b}$ & $1,53 \pm 0,06^{a b}$ & $2,21 \pm 0,04^{\mathrm{b}}$ \\
\hline $\mathrm{T} 7=\mathrm{GP} 0,50 \%$ & $79,97 \pm 0,08^{a}$ & $0,62 \pm 0,02^{a}$ & $1,47 \pm 0,06^{\mathrm{b}}$ & $2,58 \pm 0,16^{\mathrm{a}}$ \\
\hline
\end{tabular}

Médias na mesma coluna e com letras iguais não diferem significativamente entre si pelo teste de Tukey ( $<<0,05)$. Os valores correspondem à média de três repetições com estimativa do desvio padrão.

Fonte: Elaboração dos autores. 


\section{Análises microbiológicas}

Em todas as amostras de bebidas lácteas fermentadas (Tabela 4) foram obtidos o Número Mais Provável/mL (NML/mL) de coliformes totais e coliformes termotolerantes menores que 0,3 NMP/ mL. De acordo com o RTIQ de Bebidas Lácteas (BRASIL, 2005), os NMP/mL de coliformes permitidos para bebidas lácteas fermentadas são de até $100 \mathrm{NMP} / \mathrm{mL}$ de coliformes totais e $10 \mathrm{NMP} /$ $\mathrm{mL}$ de coliformes termotolerantes para amostras indicativas. Os resultados encontrados indicam qualidade higiênico-sanitária adequada durante todo o processo de produção e armazenamento das bebidas lácteas fermentadas, e demonstram qualidade microbiológica superior à exigida pela legislação vigente.

Quanto a presença de Coliformes a $35^{\circ} \mathrm{C}$ e Coliformes a $45^{\circ} \mathrm{C}$ (Tabela 4) os resultados das análises microbiológicas mostraram que, independente dos tipos de estabilizantes/espessantes e porcentagens destes, todas as amostras de bebida láctea fermentada estavam aptas ao consumo, dentro dos valores de referência para este tipo de produto (BRASIL, 2005).

Tabela 4. Análises microbiológicas das amostras de bebida láctea fermentada resultantes de dez tratamentos com diferentes proporções de estabilizantes/espessantes.

\begin{tabular}{ccc}
\hline Tratamentos & Coliformes a $^{\left.\mathbf{3 5}^{\mathbf{0}} \mathbf{C} \mathbf{( N M P} / \mathbf{m L}\right)}$ & Coliformes $\left.^{\mathbf{4}} \mathbf{4 5}^{\mathbf{0}} \mathbf{C} \mathbf{( N M P} / \mathbf{m L}\right)$ \\
\hline T1 & $<0,3$ & $<0,3$ \\
T2 & $<0,3$ & $<0,3$ \\
T3 & $<0,3$ & $<0,3$ \\
T4 & $<0,3$ & $<0,3$ \\
T5 & $<0,3$ & $<0,3$ \\
T6 & $<0,3$ & $<0,3$ \\
T7 & $<0,3$ & $<0,3$ \\
T8 & $<0,3$ & $<0,3$ \\
T9 & $<0,3$ & $<0,3$ \\
T10 & $<0,3$ & $<0,3$ \\
\hline
\end{tabular}

Os valores correspondem à média de três repetições.

Fonte: Elaboração dos autores.

Avaliação sensorial das bebidas lácteas fermentadas

As amostras T1 e T7 (Tabela 5) foram mais aceitas $(p<0,05)$ quanto os atributos aparência e cor que a amostra T3, considerando-se os valores das médias $(6,90-7,40$ e 6,94-7,22) e do IA (superior a $70 \%$ ). Com relação ao aroma e a textura a amostra T7 apresentou a maior média $(6,96$ e 7,04) e IA (superior a 70\%), diferindo da amostra T3 que foi menos aceita. As médias para todos os atributos das amostras T1 e T7 ficaram entre os termos "gostei moderadamente" a "gostei muito", enquanto as médias dos atributos da amostra T3 ficaram entre "não gostei nem desgostei" a "gostei levemente" (Tabela 5). Em relação ao IA das amostras (Tabela
6), observou-se para todos os atributos que a amostra T3 (IA inferior a 70\%) não foi aceita pelos consumidores, enquanto as amostras T1 e T7 (IA superior a 70\%) foram bem aceitas, indicando que são produtos de boa aceitação e com possibilidade de comercialização. Segundo Monteiro (1984), Teixeira, Meinert e Barbetta (1987) e Dutcosky (1996), o produto atingindo um percentual igual ou maior que $70 \%$ é considerado aceito pelos provadores. Apesar do tratamento $\mathrm{T} 1$ possuir média de aceitação e IA similar ao tratamento T7, o tratamento T1 apresentou o dobro da porcentagem de espessante na elaboração do produto, sendo o tratamento T7 mais econômico em termos percentuais (Tabela 6). 
Tabela 5. Médias de aceitação ${ }^{1}$ das amostras de bebida láctea fermentada resultantes de três tratamentos com diferentes proporções de estabilizantes/espessantes.

\begin{tabular}{lcccc}
\hline \multirow{2}{*}{ Tratamentos } & \multicolumn{4}{c}{ Atributos } \\
\cline { 2 - 5 } & Aparência & Aroma & Cor & Textura \\
\hline T1 = PCPS 1,00\% & $6,90 \pm 1,63^{\mathrm{a}}$ & $6,74 \pm 1,38^{\mathrm{ab}}$ & $6,94 \pm 1,35^{\mathrm{a}}$ & $6,34 \pm 1,86^{\mathrm{ab}}$ \\
T3 = GG 1,00\% & $5,76 \pm 2,25^{\mathrm{b}}$ & $6,24 \pm 1,39^{\mathrm{b}}$ & $5,52 \pm 1,93^{\mathrm{b}}$ & $5,52 \pm 2,57^{\mathrm{b}}$ \\
T7 = GP 0,50\% & $7,40 \pm 1,25^{\mathrm{a}}$ & $6,96 \pm 1,55^{\mathrm{a}}$ & $7,22 \pm 1,33^{\mathrm{a}}$ & $7,04 \pm 1,86^{\mathrm{a}}$ \\
\hline
\end{tabular}

Médias na mesma coluna e com letras iguais não diferem significativamente entre si pelo teste de Tukey $(\mathrm{p}<0,05), \mathrm{n}=50$ julgadores. ${ }^{1}$ Escala hedônica estruturada de nove pontos $(1=$ desgostei muitíssimo; $9=$ gostei muitíssimo $)$. Os valores correspondem à média com estimativa do desvio padrão.

Fonte: Elaboração dos autores.

Em relação à aceitação da amostra T7, os resultados foram semelhantes aos encontrados por Jawalekar et al. (1993) que utilizaram a gelatina como estabilizante/espessante na formulação de iogurte a base de leite de vaca e de búfala. Já Koksoy e Kilic (2004), utilizando 0,5\% de gelatina na produção da bebida de iogurte (ayran), obtiveram uma bebida considerada inaceitável em relação ao gosto e odor. Kumar e Mishra (2004) estudaram o efeito da adição de três estabilizantes/ espessantes (gelatina, pectina e alginato de sódio), nas proporções de $0,2 \%, 0,4 \%$ e $0,6 \%$, sobre as propriedades físico-químicas, sensoriais e de textura em "iogurte de soja" fortificado com manga. Constataram que, em relação à aceitação sensorial, a adição de $0,4 \%$ de gelatina melhorou a aparência, cor, textura e aceitabilidade geral das amostras, em comparação com os outros estabilizantes.
Estes resultados são similares aos obtidos no tratamento T7 com $0,5 \%$ de gelatina (Tabela 5) que também apresentou melhores níveis de aceitação. Manzano et al. (2008) avaliaram o efeito de fécula de inhame, amido modificado e gelatina como espessantes/estabilizantes em diferentes proporções e combinações em "iogurte" de soja fermentado e concluíram que os dez diferentes tipos de tratamentos no teste de aceitação não diferiram significativamente $(\mathrm{p}<0,05)$ para o atributo textura, mas o mesmo não ocorreu nos resultados obtidos no referido estudo que mostraram diferença $(p<0,05)$ de aceitação entre as amostras adicionadas de goma guar $(1,00 \%)$ e gelatina $(0,50 \%)$. Entretanto, corroborando com os resultados dos mesmos autores, para o atributo textura (em termos de valores absolutos), o tratamento adicionado de gelatina $(0,50 \%)$ obteve os melhores resultados de aceitação (Tabela 5).

Tabela 6. Índice de aceitação (\%) das amostras de bebida láctea fermentada resultantes de três tratamentos com diferentes proporções de estabilizantes/espessantes.

\begin{tabular}{lcccc}
\hline \multirow{2}{*}{ Tratamentos } & \multicolumn{3}{c}{ Atributos } \\
\cline { 2 - 5 } & Aparência & Aroma & Cor & Textura \\
\hline T1 = PCPS 1,00\% & 76,67 & 74,89 & 77,11 & 70,44 \\
T3 = GG 1,00\% & 64,00 & 69,33 & 61,33 & 61,33 \\
T7 = GP 0,50\% & 82,22 & 77,33 & 80,22 & 78,22 \\
\hline
\end{tabular}

Os valores correspondem às percentagens do índice de aceitação para os atributos avaliados, $\mathrm{n}=50$ julgadores.

Fonte: Elaboração dos autores. 


\section{Conclusões}

As amostras adicionadas de $1 \%$ proteína e concentrado proteico de soro (T1) e $0,5 \%$ de gelatina (T7) apresentaram ausência de sinérese e viscosidade/consistência similiar/compatível com bebidas lácteas fermentadas comerciais, sendo aceitas pelos consumidores (IA acima de 70\%) quanto aos atributos de aparência aroma, sabor e textura. O produto elaborado com $0,5 \%$ de gelatina, com metade da porcentagem de estabilizante/ espessante, destacou-se pela maior viscosidade/ consistência, ausência de sinérese e melhor índice de aceitação sensorial.

\section{Agradecimentos}

À Fundação de Amparo à Pesquisa do Estado de Goiás (FAPEG) pela bolsa de Doutorado, à Coordenação de Aperfeiçoamento de Pessoal de Nível Superior (CAPES) pelo apoio financeiro, ao Centro de Pesquisa em Alimentos e ao Departamento de Engenharia de Alimentos da Universidade Federal de Goiás pelo desenvolvimento da pesquisa.

\section{Referências}

ALMEIDA, K. E.; BONASSI, I. A.; ROÇA, R. O. Características físicas e químicas de bebidas lácteas Fermentadas e preparadas com soro de queijo minas frescal. Ciência e Tecnologia de Alimentos, Campinas, v. 21, n. 2, p. 187-192, maio/ago. 2001.

ALVES, C. C. C. Comportamento da Escherichia coli em queijo minas frescal elaborado com utilização de Lactobacillus acidophifilus e de acidificação direta com ácido lático. 2010. Dissertação (Mestrado em Medicina Veterinária) - Universidade Federal Fluminense, Niterói.

ANDRADE, E. H. P. Qualidade físico-química, microbiológica e detecção de soro lácteo por cromatografia líquida de alta eficiência em bebidas lácteas fermentadas. 2010. Dissertação (Mestrado em Ciência Animal) - Universidade Federal de Minas Gerais, Escola de Veterinária, Belo Horizonte.

ANDRADE, R. L. P.; MARTINS, J. F. P. Influência da adição da fécula de batata-doce (Ipomoea batatas L.) sobre a viscosidade do permeado de soro de queijo. Ciência e Tecnologia de Alimentos, Campinas, v. 22, n. 3, p. 249-253, 2002.

ANTUNES, A. E. C.; CAZETTO, T. F.; BOLINI, H. M. A. Skim yogurts added by whey protein concentrate: texture profile, syneresis and sensorial analysis. Alimentos $e$ Nutrição, Marília, v. 15, n. 2, p. 105-114, 2004.

ARANCIBIA, C.; JUBLOT, L.; COSTELL, E.; BAYARRI, S. Flavor release and sensory characteristics of $\mathrm{o} / \mathrm{w}$ emulsions. Influence of composition, microstructure and rheological behavior. Food Research International, Barking, v. 44, n. 6, p. 1632-1641, 2011.

BASTIANI, M. I. D. Iogurte adicionado de concentrado proteico de soro de leite e farinha de linhaça: desenvolvimento, qualidade nutricional e sensorial. 2009. Tese (Doutorado em Ciência e Tecnologia de Alimentos) - Universidade Federal de Viçosa, Viçosa.

BAYARRI, S.; CHULIÁ, I.; COSTELL, E. Comparing $\lambda$-carrageenan and an inulin blend as fat replacers in carboxymethyl cellulose dairy desserts. Rheological and sensory aspects. Food Hydrocolloids, Oxford, v. 24, n. 6-7, p. 578-587, 2010.

BELLARDE, F. B. Elaboração de doce de leite pastoso com substituição parcial de sólidos do leite por concentrado proteico do soro. Revista Uniara, Araraquara, v. 1, n. 17-18, p. 249-255, 2006.

BRASIL. Ministério da Agricultura, Pecuária e Abastecimento. Secretaria de Inspeção de Produto Animal. Instrução Normativa $n^{\circ} 62$ de 26 de agosto de 2003. Oficializa os métodos analíticos oficiais para análises microbiológicas para controle de produtos de origem animal e água. Diário Oficial [da] República Federativa do Brasil, Brasília, DF, 18 de setembro de 2003. Seção 1, p. 14.

Instrução Normativa $n^{\circ} 46$ de 23 de outubro de 2007. Adota o Regulamento Técnico de Identidade e Qualidade de Leites Fermentados. Diário Oficial [da] República Federativa do Brasil, Brasília, DF, 24 de outubro de 2007. Seção 1, p. 5.

Instrução Normativa, n 1 de 7 de

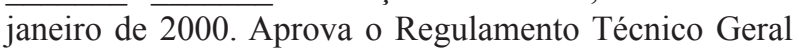
para fixação dos Padrões de Identidade e Qualidade para Polpa de Fruta. Diário Oficial [da] União, Brasília, DF, 10 de janeiro de 2000. Seção 1, p. 54.

. Secretaria de Inspeção de Produto Animal. Instrução Normativa ${ }^{\circ} 68$, de 12 de dezembro de 2006. Oficializa os Métodos Analíticos Oficiais FísicoQuímicos, para Controle de Leite e Produtos Lácteos, em conformidade com o anexo desta Instrução Normativa, 
determinando que sejam utilizados nos Laboratórios Nacionais Agropecuários. Diário Oficial [da] República Federativa do Brasil, Brasília, DF, 14 de dezembro de 2006. Seção 1, p. 8.

Secretaria de Inspeção de Produto

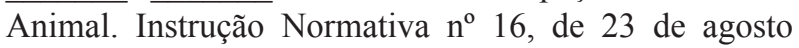
de 2005. Aprova o Regulamento técnico de Identidade e Qualidade de Bebidas Lácteas. Diário Oficial [da] República Federativa do Brasil, Brasília, DF, 24 de agosto de 2005. Seção 1, p. 7.

CALDEIRA, L. A.; FERRÃO, S. P. B.; FERNANDES, S. A. A.; MAGNAVITA, A. P. A.; SANTOS, T. D. R. Desenvolvimento de bebida láctea sabor morango utilizando diferentes níveis de iogurte e soro lácteo obtidos com leite de búfala. Ciência Rural, Santa Maria, v. 40, n. 10, p. 2193-219, 2010.

CRUZ, A. G.; SANT'ANA, A. S.; MACCHIONE, M. M.; TEXEIRA, A. S.; SCHMIDT, F. L. Milk drink using whey butter cheese (queijo manteiga) and acerola juice as a potential source of vitamin C. Journal of Food and Bioprocess Technology, Heidelberg, v. 2, n. 4, p. 368373, 2008.

DANNENBERG, F.; KESSLER, H. G. Effect of denaturation of -lactoglobulin on texture properties of set-style nonfat yoghurt. 2. Firmeness and flow properties. Milchwissenschaft, Munchen, v. 43, n. 11, p. 700-704, 1988.

DICKINSON, E. Hydrocolloids as emulsifiers and emulsion stabilizers. Food Hydrocolloids, Oxford, v. 23, n. 6, p. 1473-1782, 2009.

DUTCOSKY, S. D. Análise sensorial de alimentos. Curitiba: Editora Champagnat, 1996. 123 p.

DZIEZAK, J.D. A focus on gums. Food Technology, Chicago, v. 45, n. 3, p. 117-132, 1991.

FISZMAN, S. M.; LLUCH, M. A.; SALVADOR, A. Effect of addition of gelatin on microstructure of acidic milk gels and yoghurt and on their rheological properties. International Dairy Journal, Barking, v. 9, n. 12, p. 895901, dez. 1999.

GALLARDO-ESCAMILLA, F. J.; KELLY, A. L.; DELAHUNTY, C. M. Mouthfeel and flavour of fermented whey with added hydrocolloids. International Dairy Journal, Barking, v. 17, n. 4, p. 308-315, 2007.

GOMES, R. G.; PENNA, A. L. B. Características reológicas e sensoriais de bebidas lácteas funcionais. Semina: Ciências Agrárias, Londrina, v. 30, n. 3, p. 629646, 2009.
GONZÁLEZ-TOMÁSA, L.; BAYARRIA, S.; TAYLOR, A. J.; COSTELL, E. Rheology, flavour release and perception of low-fat dairy desserts. International Dairy Journal, Barking, v. 18, n. 2, p. 858-866, ago. 2008.

HOFMEISTER, L. C.; SOUZA, J. A. R.; PETRUS, J. C. C.; LAURINDO, J. B. Salga de queijo tipo minas por impregnação a vácuo. Ciência e Tecnologia de Alimentos, Campinas, v. 25, n. 3, p. 487-494, jul./set. 2005.

HUFFMAN, L. M. Processing whey protein for use as a food ingredient. Food Technology, Chicago, v. 50, n. 2, p. 49-52, 1996.

JANHØJ, T.; FRØST, M. B.; IPSEN, R. Sensory and rheological characterization of acidified milk drinks. Food Hydrocolloids, Oxford, v. 22, n. 5, p. 798-806. jul. 2008.

JAWALEKAR, S. D.; INGLE, U. M.; WAGHMARE, P. S. S.; ZANJAD, P. N. Influence of hydrocolloids on rheological and sensory properties of cow and buffalo's yoghurt. Indian Journal of Dairy Science, New Delhi, v. 63, n. 1, p. 217-219, 1993.

KEOGH, M. K.; O'KENNEDY, B. T. Rheology of stirred yoghurt as affected by added milk fat, protein and hydrocolloids. Journal of Food Science, Chicago, v. 63, n. 1, p. 108-112, 1998.

KOKSOY, A.; KILIC, M. Use of hydrocolloids in textural stabilization of a yoghurt drink, ayran. Food Hydrocolloids, Oxford, v. 18, n. 4, p. 593-600, jul. 2004.

KUMAR, P.; MISHRA, H. N. Mango soy fortified set yoghurt: effect of stabilizer addition on physicochemical, sensory and textural properties. Food Chemistry, London, v. 87, n. 4, p. 501-507, out. 2004.

MALI, S.; FERRERO, C.; REDIGONDA, V.; BALEIA, A. P.; GROSSMANN, M. V. E.; ZARITZKY, N. E. Influence of $\mathrm{pH}$ and hydrocolloids addition on yam (Dioscorea alata) starch pastes stability. LWT - Food Science and Technology, London, v. 36, n. 5, p. 475-481, 2003.

MANZANO, G. P. P.; DAIUTO, E. R.; JANZANTTI, N. S.; ROSSI, E. A. Aspectos sensoriais e físico-químicos de "iogurtes" de soja com espessantes/estabilizantes a base de fécula de inhame (Dioscorea alata), amido modificado e gelatina. Boletim do Centro de Pesquisa e Processamento de Alimentos, Curitiba, v. 26, n. 2, p. $287-$ 296, jul./dez. 2008.

MARCOTTE, M.; HOSHAHITI, A. R T.; RAMASWAMY, H. S. Rheological properties of selected hydrocolloids as a function of concentration and temperature. Food Research International, Barking, v. 34, n. 8, p. 695-703, 2001. 
MARTINS, S. C. S. G.; ROCHA JÚNIOR, V. R.; CALDEIRA, L. A.; REIS, S. T.; BARROS, I. C.; OLIVEIRA, J. A.; SANTOS, J. F.; SILVA, G. W. V. Rendimento, composição e análise sensorial do queijo minas frescal fabricado com leite de vacas mestiças alimentadas com diferentes volumosos. Revista Brasileira de Zootecnia, Viçosa, v. 41, n. 4, p. 993-1003, 2012.

MATOS, R. A. Desenvolvimento e mapa de preferência externo de bebida láctea a base de soro e polpa de graviola (Annona muricata). 2009. Dissertação (Mestrado em Engenharia de Alimentos) - Universidade Estadual do Sudoeste da Bahia, Itapetinga.

MCCLEMENTS, D. J. Critical review of techniques and methodologies for characterization of emulsion stability. Critical Reviews in Food Science and Nutrition, Boca Raton, v. 47, n. 7, p. 611-649, 2007.

MENEZES, A. C. S. Desenvolvimento de bebida láctea fermentada à base de soro de leite e polpa de cajá (Spondias mombin L.) com potencial atividade probiótica. 2011. Dissertação (Mestrado em Ciência e Tecnologia de Alimentos) - Universidade Federal Rural de Pernambuco, Recife.

MINIM, V. P. R. Análise sensorial: estudos com consumidores. Viçosa: Ed. UFV, 2010. 308 p.

MONTEIRO, C. L. B. Técnicas de avaliação sensorial. 2. ed. Curitiba: CEPPA-UFPR, 1984. 101 p.

OLIVEIRA, V. M.; CORTEZ, M. A. S.; FREITAS, M. Q.; FRANCO, R. M. Avaliação sensorial de bebida láctea fermentada com diferentes concentrações de soro de queijo, enriquecida com ferro. Revista Brasileira de Ciência Veterinária, Niterói, v. 13, n. 2, p. 67-70, 2006.

R DEVELOPMENT CORE TEAM. $R$ : a language and environment for statistical computing, reference index version 2.11.1 (2010-05-31). Vienna: The R Foundation for Statistical Computing, Austria, 2010.

REGESTER, G. O.; McINTOSH, G. H.; LEE, V. W. K.; SMITHERS, G. W. Whey proteins as nutritional and functional food ingredients. Food Australia, North Sydney, v. 48, n. 3, p. 123-128, 1996.

RIENER, J.; NOCI, F.; CRONIN, D. A.; MORGAN, D. J.; LYNG, J. G. A comparison of selected quality characteristics of yoghurts prepared from thermosonicated and conventionally heated milks. Food Chemistry, London, v. 119, n. 3, p. 1108-1113, abr. 2010.

ROSSI, E. A.; REDDY, K. V.; SILVA, R. S. S. F. Formulation of soy-whey yogurt, using response surface methodology. Arquivos de Biologia e Tecnologia, Curitiba, v. 27, n. 3, p. 387-390, 1984.
SANDERSON, G. R. Gums and their use in food systems. Food Technology, Chicago, v. 50, n. 3, p. 81-84, 1996.

SANDOVAL-CASTILLAA, O.; LOBATOCALLEROSA, C.; AGUIRRE-MANDUJANOA, E.; VERNON-CARTER, E. J. Microstructure and texture of yogurt as influenced by fat replacers. International Dairy Journal, Barking, v. 14, n. 2, p. 151-159, fev. 2004.

SANTOS, C. T.; COSTA, A. R.; FONTAN, G. C. R.; FONTAN, R. C. I.; BONOMO, R. C. F. Influência da concentração de soro na aceitação sensorial de bebida láctea fermentada com polpa de manga. Alimentos $e$ Nutrição, Marília, v. 19, n. 1, p. 55-60, jan./mar. 2008.

SANTOS, C. T.; MARQUES, G. M. R.; FONTAN, G. C. R.; FONTAN, R. C. I.; BONOMO, R. C. F.; BONOMO, P. Elaboração e caracterização de uma bebida láctea fermentada com polpa de umbu (Spondias tuberosa sp.). Revista Brasileira de Produtos Agroindustriais, Campina Grande, v. 8, n. 2, p. 111-116, 2006.

SILVA, D. C. G.; ABREU, L. R.; ASSUMPÇÃO, G. M. $P$. Addition of water-soluble soy extract and probiotic culture, viscosity, water retention capacity and syneresis characteristics of goat milk yogurt. Ciência Rural, Santa Maria, v. 42, n. 3, p. 545-550, mar. 2012.

SINHÁ, R.; RADHA, C.; PRAKASH, J.; KAUL, P. Whey protein hydrolysate: Functional properties, nutritional quality and utilization in beverage formulation. Food Chemistry, London, v. 101, n. 4, p. 1484-1491, 2007.

SMITHERS, G. W. Whey and whey proteins - from 'gutter to gold'. International Dairy Journal, Barking, v. 18, n. 7, p. 695-704, 2008.

SODINI, I.; MONTELLA, J.; TONG, P. S. Physical and rheological properties of yogurt fortified with various whey protein concentrates. Journal of the Science of Food and Agriculture, London, v. 85, n. 5, p. 853-859, 2005.

SOUZA, G. Fatores de qualidade do iogurte. Coletânea do Instituto de Tecnologia de Alimentos, Piracicaba, v. 21, n. 1, p. 20-27, 1991.

STONE, H.; SIDEL, J. L. Sensory evaluation practices. 3. ed. London: Elsevier Academic Press, 2004. 377 p.

SUPAVITITPATANA， P.; WIRJANTORO, T. I.; APICHARTSRANGKOON, A.; RAVIYAN, P. Addition of gelatin enhanced gelation of corn-milk yogurt. Food Chemistry, London, v. 106, n. 1, p. 211-216, 2008.

TEIXEIRA, E.; MEINERT, E. M.; BARBETTA, P. A Métodos sensoriais. In: TEIXEIRA, E.; MEINERT, E. M.; BARBETA, P. A.. Análise sensorial de alimentos. Florianópolis: Editora da UFSC, 1987. p. 66-119. 
THAMER, K. G.; PENNA, A. L. B. Caracterização de bebidas lácteas funcionais fermentadas por probióticos e acrescidas de prebiótico. Ciência e Tecnologia de Alimentos, Campinas, v. 26, n. 3, p. 589-595, jul./set. 2006.

WEBER, F. H. Interações físico-químicas entre amidos de milho e hidrocolóides (gomas guar e xantana) e seus efeitos nas propriedades funcionais. 2005. Tese (Doutorado em Tecnologia de Alimentos) - Faculdade de Engenharia de Alimentos, Universidade Estadual de Campinas, Campinas.

YOO, S. S.; KOOK, S. H.; PARK, S. Y.; SHIM, J. H.; CHIN, K. B. Physicochemical characteristics, textural properties and volatile compounds in comminuted sausages as affected by various fat levels and fat replacers. International Journal of Food Science \& Technology, Oxford, v. 42, n. 9, p. 1114-1122, 2007. 